\title{
Respiratory health effects of residential individual and cumulative risk factors in children living in two cities of the Pearl River Delta Region, China
}

\author{
Jianqing Lin ${ }^{1 \#}$, Weiwei Lin ${ }^{1 \#}$, Zixuan Yin ${ }^{2}, \mathrm{Xi} \mathrm{Fu}^{1}$, Dejian Mai ${ }^{1}$, Shaojie Fu ${ }^{1}$, Junfeng Jim Zhang ${ }^{3,4,5}$, \\ Jicheng Gong ${ }^{6}$, Ning Feng ${ }^{2}$, Lingyan $\mathrm{He}^{2}$
}

${ }^{1}$ Department of Occupational and Environmental Health, School of Public Health, Sun Yat-Sen University, Guangzhou 510080, China; ${ }^{2}$ Key Laboratory for Urban Habitat Environmental Science and Technology, School of Environment and Energy, Peking University Shenzhen Graduate School, Shenzhen 518055, China; ${ }^{3}$ Nicholas School of Environment \& Duke Global Health Institute, Duke University, Durham, USA; ${ }^{4}$ Duke Kunshan University, Kunshan 215316, China; ${ }^{5}$ Guangzhou Institute of Respiratory Health, The First Affiliated Hospital of Guangzhou Medical University, Guangzhou 510120, China; ${ }^{6}$ Beijing Innovation Center for Engineering Science and Advanced Technology, State Key Joint Laboratory for Environmental Simulation and Pollution Control, College of Environmental Sciences and Engineering, and Center for Environment and Health, Peking University, Beijing 100871, China

Contributions: (I) Conception and design: W Lin, L He, JJ Zhang, J Gong; (II) Administrative support: N Feng; (III) Provision of study materials or patients: W Lin, N Feng, L He; (IV) Collection and assembly of data: J Lin, Z Yin, D Mai, S Fu; (V) Data analysis and interpretation: J Lin, W Lin, $\mathrm{X}$ Fu; (VI) Manuscript writing: All authors; (VII) Final approval of manuscript: All authors.

\#These authors contributed equally to this work.

Correspondence to: Weiwei Lin. Department of Occupational and Environmental Health, School of Public Health, Sun Yat-Sen University, Yuexiu District, Guangzhou 510080, China. Email: linweiw5@mail.sysu.edu.cn; Lingyan He. Key Laboratory for Urban Habitat Environmental Science and Technology, School of Environment and Energy, Peking University Shenzhen Graduate School, Shenzhen 518055, China. Email: hely@pku.edu.cn.

Background: Indoor environment is complex, with many factors potentially interacting with each other to affect health. However, previous studies have usually focused on effect of a single factor. Assessment of the combined effects of multiple factors can help with understanding the overall health risk.

Methods: A cross-sectional study was conducted among 2,306 school children in Guangzhou and Shenzhen. Questionnaire data on respiratory symptoms and diseases were collected along with sociodemographic and residential environmental information. A subset of children $(\mathrm{N}=987)$ were measured for their lung function. A random forest algorithm was applied to screen the top-ranked indoor environmental exposure variables and to form a composite index for cumulative risk of indoor pollution (CRIP). Logistic regressions were conducted to analyze the independent effect of single indoor environmental risk factors and the combined effect of CRIP on children's respiratory health. Multiple linear regressions were used to examine the independent and combined effects of indoor environmental exposure on lung function.

Results: We found that home dampness and molds as well as environmental tobacco smoke (ETS) were significantly and independently associated with increased prevalence of children's respiratory symptoms and diseases and with reduced lung function. A higher CRIP level was significantly associated with increased risk of cough with cold (OR =1.37, 95\% CI: 1.05-1.79) and wheeze (OR =2.71, 95\% CI: 1.16-6.34). A higher $\mathrm{CRIP}$ level was also associated with reduced lung function measured as FVC, FEV 1 , PEF, FEF $25 \%, \mathrm{FEF}_{25-75 \%}$ and VC.

Conclusions: In children living in the subtropical region of the Pearl River Delta, home dampness and the presence of mold as well as ETS were individual risk factors for children's respiratory health. The composite CRIP index was associated with respiratory symptoms and lung function, suggesting the utility of this index for predicting the combined effects of multiple risk factors. 
Keywords: Indoor environment; children; respiratory diseases and respiratory symptoms; lung function; cumulative risk

Submitted Nov 13, 2019. Accepted for publication Mar 16, 2020.

doi: $10.21037 /$ jtd.2020.03.92

View this article at: http://dx.doi.org/10.21037/jtd.2020.03.92

\section{Introduction}

Children spend $80-90 \%$ of their time indoors. Due to their developing physiology, children are often more susceptible to indoor pollution (1-3). Indoor pollution sources such as cooking, environmental tobacco smoke (ETS), dampness and molds, chemicals off-gassed from consumer products, may increase the risk for the development of asthma, reduce lung function (4-6), increase airway hyperresponsiveness, and elevate the prevalence and/or incidence of respiratory symptoms in children (4-10). Indoor environment may be associated with many factors potentially interacting with each other and affecting each other. However, previous studies have mainly focused on single exposure factors when exploring the health risks relevant to indoor environment. This is not consistent with the fact that health risks are the results of combined actions of multiple exposure factors.

In an attempt to overcome the existing limitation, we developed a method for integrating multiple indoor exposure factors. On the basis of the random forest algorithm, the method aimed to identify high-priority indoor environmental risk factors and generated a composite index for indoor environmental exposure. The random forest algorithm is a powerful classification and regression approach capable of measuring variable importance and identifying the interaction of variables to enhance the predictive accuracy (11). It has the major advantages of preventing overfitting and producing improved predictive accuracy, therefore has gained considerable popularity in the field of bioinformatics (12-15). The data analysis in our study for identifying the most important indoor health risk factors is inspired by the application of random forest in bioinformatics that has been developed to screen the genes most relevant to diseases.

In this context, we analyzed data collected in a crosssectional study of 2,306 children in the cites of Guangzhou and Shenzhen, China. The purpose of the present analysis was two-fold. First, we aimed to explore the health effects of individual indoor environmental risk factors. Secondly, we used a random forest algorithm to form a composite risk index integrating most important individual risk factors, aiming at assessing the cumulative risk of indoor pollution (CRIP).

\section{Methods}

\section{Study design}

Our study draws from an extended study of the Four Chinese Cities Study (4CC study) which was originally conducted in 1993-1997 (16). The current study conducted in 2018 was a follow-up of the 4CC study to explore the health effects of the changes in environmental risk factors over 20 years (17). Similar to the 4CC study, children were sampled from two elementary schools located in urban and suburban of each city in the current extended study. As part of the larger 4CC study, our study was undertaken in the cities of Guangzhou and Shenzhen. As one of the cities with the fastest economic development in China, Guangzhou has extensively expanded its urban areas in the past 20 years, resulting in high urbanization of suburban areas and spatial homogeneity of air pollution across urban and suburban areas. To better reflect the heterogeneity in environmental pollution effects, the city of Shenzhen, located about 150 $\mathrm{km}$ southeast of Guangzhou, was introduced into our current study as a contrast area of Guangzhou (Figure 1). Shenzhen has similar climate to Guangzhou but with generally lower air pollution levels. Both of the cities are within the Pearl River Delta region with warm and humid weather. The mean annual temperature ranges from 14 to $22{ }^{\circ} \mathrm{C}$ and annual precipitation is $1,525.1 \mathrm{~mm}$ (18). Hence buildings in these cities are highly vulnerable to indoor dampness and mold. Two elementary schools, one located at Huangpu District, Guangzhou, and the other in university town of Nanshan District, Shenzhen, were selected for the study. Both schools were located at the upwind areas of the Pearl River Delta region and less than 100 meters distant from the nearest main road. There are no obvious industrial pollution sources within a radius of $1 \mathrm{~km}$ from the schools. Children in grades 1 to 6 were all recruited from 


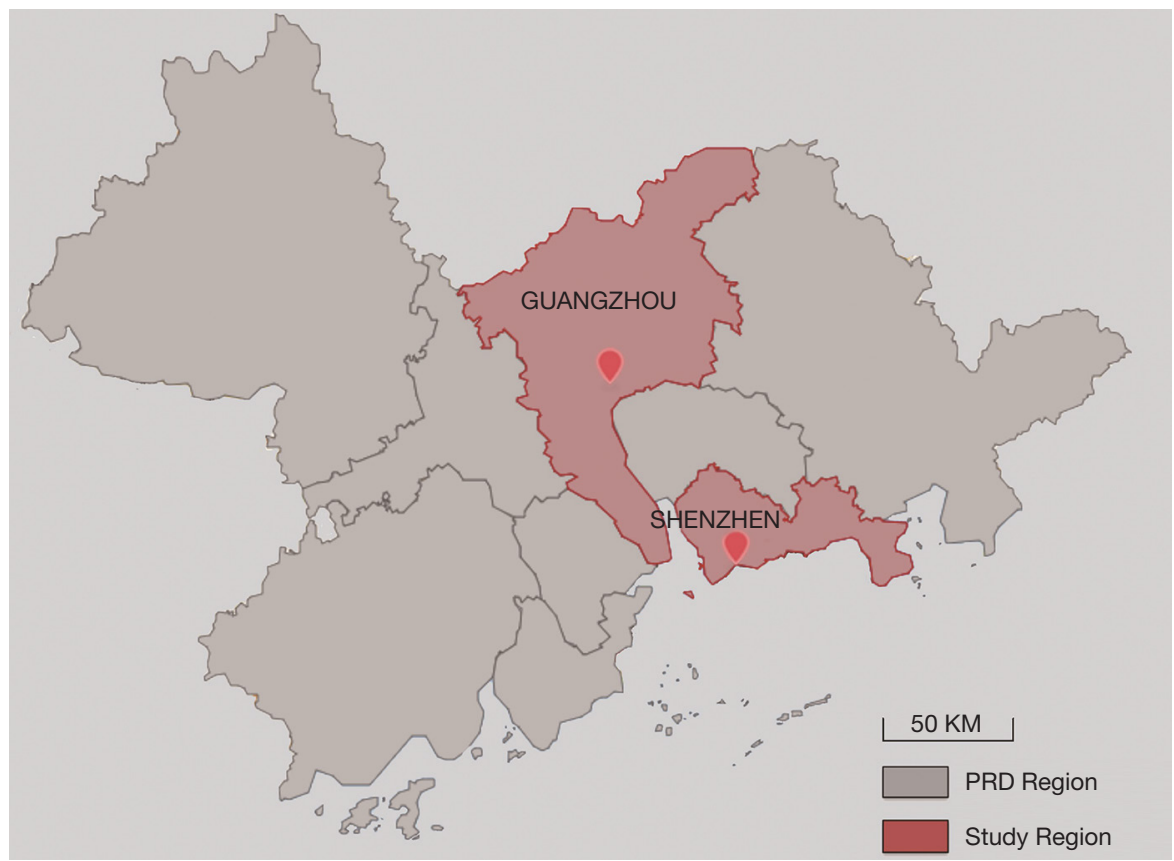

Figure 1 Map of the Pearl River Delta Region showing the schools from which children were enrolled into the study.

each school from December, 2017 to May, 2018. We used a unified study protocol for questionnaire survey and lung function measurement. The standardized questionnaires were used to collect data on environmental exposure and respiratory symptoms and diseases. Lung function was measured using the same models of spirometers following the same QA/QC guidelines. This study was approved by the Duke Kunshan University Institutional Review Board (DKU IRB) (No. FWA00021580). Informed consent forms were obtained from parents or guardians of the children before they participated in the study.

\section{Questionnaire survey}

Questionnaires were completed by children's parents to obtain information on household characteristics (e.g., ETS exposure, stove/fuel type, cooking habit, kitchen type, ventilation pattern, home dampness and molds), children's respiratory health status, parental information (including health histories, occupation and education). The questionnaire, which had previously been validated in the 4CC study (16), was a modified version of the American Thoracic Society Epidemiologic Standardization Project questionnaire (19). We asked 2,765 families (1,565 in Guangzhou and 1,200 in Shenzhen) to fill out the study questionnaire and received 2,420 questionnaires (response rate $=87.5 \%$ ). After excluding those with missing data, 2306 were included in our analysis. For the present study, we used all the indoor environment variables and respiratory symptoms/diseases variables (Table 1) collected in the questionnaires.

The indoor environment characteristics (potential risk factors) are defined as following:

Dampness and molds: there were visible molds in the house due to dampness in the past 12 months; ETS: child lived with any family members who were smokers; incense burning: Household burned incense stick or mosquitorepellent incense during summer; open kitchen: child's residence had an open kitchen; decoration: child residence was decorated (e.g., interior remodeling, new furnishing, and new surface painting) in the past 12 months; cooking frequency: this was classified as "high" if child's home cooked for more than 3 days a week and "low" if cooked $\leq 3$ days/week; pets: child's household kept one or more pets at home; air conditioner: child's household used air conditioning for more than 5 hours a day in any one of the four seasons; kitchen ventilation: household used a mechanical ventilator in the kitchen, including exhaust fan or smoke exhaust ventilator; non-clean fuels: household used gas or solid fuels for cooking (reference is electricity 
Table 1 The definition of the 18 respiratory symptoms and diseases

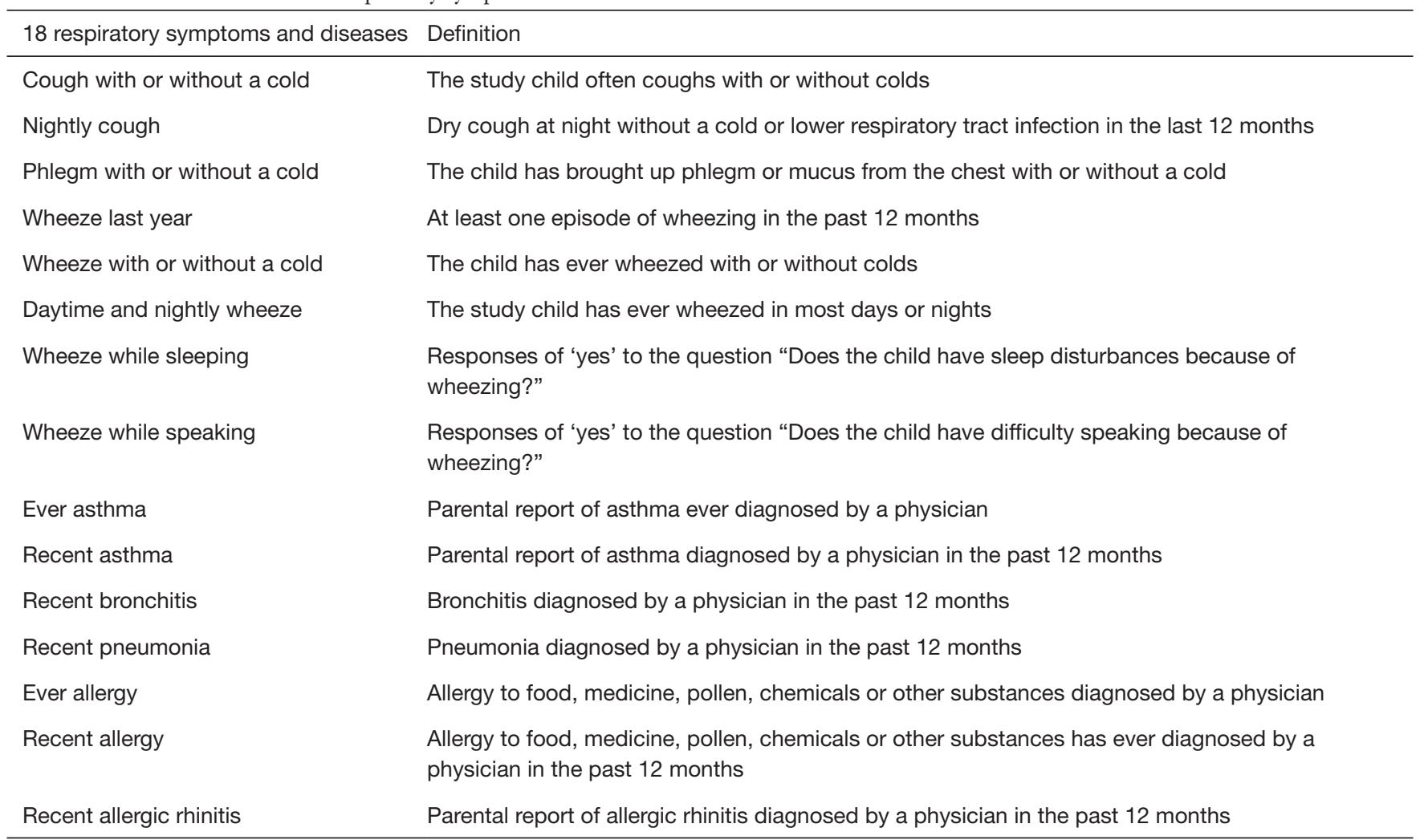

for cooking); air freshener: household used air fresheners at home.

\section{Lung function measurement}

Among the children who had complete questionnaire data as described above, 1,044 students aged 5-13 years with the male-to-female ratio of $1: 1$ in grades 1 to 6 were selected for lung function tests by stratified random sampling. Approximately equal number of students were selected from each grade in each of the two schools. After excluding those with missing data in the questionnaire and with invalid values for their lung function measure, 987 children (484 from Guangzhou and 503 from Shenzhen) were included in the data analysis.

Lung function was measured using a spirometer (Spirolab III, Medical International Research, Rome, Italy) by trained research technicians according to the American Thoracic Society guideline. Children were instructed to perform the lung function test in a standing position wearing a nose clip. The best of three acceptable spirometry maneuvers was selected. The following lung function variables were included in our data analyses: forced vital capacity (FVC), forced expiratory volume in the first second $\left(\mathrm{FEV}_{1}\right)$, peak expiratory flow (PEF), forced expiratory flow at $25 \%$ of expired volume $\left(\mathrm{FEF}_{25 \%}\right)$, forced expiratory flow between $25 \%$ and $75 \%$ of expired volume $\left(\mathrm{FEF}_{25-75 \%}\right)$, forced expiratory flow at $75 \%$ of expired volume $\left(\mathrm{FEF}_{75 \%}\right)$, maximum voluntary ventilation (MVV), and vital capacity (VC).

\section{Statistical analysis}

\section{Variable importance ranking by random forest algorithm}

We identified high-priority indoor environmental risk factors using machine learning algorithm of random forest. Random forest has prominent performance in classification and regression, and is capable of providing variable importance measures to examine the extent to which each variable contributes to the estimate of magnitude of effect as a part of the results. The variable importance measures based on the random forest are dependent on Mean Decrease Gini; the larger the value of the indicator is, the more important the variable is (11). Our study included 
11 indoor environmental risk factors (i.e., home dampness and molds, ETS exposure, incense burning, open kitchen, household decoration, cooking frequency, pets, use of air conditioner, kitchen ventilation, cooking fuels, and use of air freshener) and 18 health outcomes. Based on the Gini index, we evaluated the importance of 11 indoor environmental risk factors and ranked their risks. The 11 indoor variables were ranked in the order of smallest to largest in variable importance measures from each forest $(\mathrm{N}=18)$. We then assigned a weight to each indoor variable corresponding to the ranks where a variable appeared. Finally, the total score of variable importance measures for each variable was obtained by summing up its weight within each ranked list. More information is provided in supplementary material (see supplementary and Table S1).

\section{Association between indoor exposure variables and health outcomes}

We used both simple and multiple logistic regression models to analyze the relationship between selected indoor risk factors and respiratory diseases or symptoms. Age, maternal education, breastfeeding duration, maternal smoking during pregnancy, maternal asthma, paternal asthma and other covariates were adjusted in the logistic regression models. When examining the relationship between indoor exposure variables and lung function, we used multivariate linear regression models in which lung function data were natural logarithm transformed and child's age, sex, height, and weight were included as covariates. The exponentiated values of regression coefficients from the linear regression models represent the percentage changes in lung function associated with the change in an exposure variable from the reference level.

\section{Assessment of CRIP}

The results from the simple logistic regression showed that the presence of pets was a protective factor for children's respiratory health in our study (Table S2). As the purpose of this study was to identify the effect of household environmental risk factors, we excluded the presence of pets; and the first six risk variables with high scores were included in an integrated model. The six variables in the model were home dampness and molds, ETS, incense burning, open kitchen, household decoration, and cooking frequency. We integrated these 6 variables to generate a comprehensive index named the CRIP, which we developed for use in this study to assess the cumulative risk of multiple indoor environmental exposures. The CRIP models were shown in Figure $S 1 A, B$. The six risk factors were defined as binary variables. The hierarchical arrangement referred to the ranked list of the six risk factors using variable importance measures from the random forest. If four out of the six risk variables were considered as 'high risk', higher CRIP was assigned to the child. Logistic regressions and multivariate linear regressions were used to examine the association of CRIP with respiratory diseases and lung function, respectively.

The random forest analyses were performed by the random Forest package in R 2.5.3 (version 4.6-14, R Foundation for Statistical Computing, Vienna, Austria). Logistic regression and multiple linear regression models were performed using Stata (version 15.0; Stata Corp LP, College Station, TX, USA).

\section{Results}

\section{Description analysis}

The characteristics of the study objects and indoor exposure variables are shown in Table 2. Among the 2,306 children, 253 were excluded from analysis due to missing data. More than $50 \%$ of mothers had received undergraduate education or higher. The prevalence of maternal asthma and paternal asthma was each below $1.0 \%$. The proportion of maternal smoking during pregnancy was low $(0.45 \%)$. However, $44.83 \%$ of the children were reportedly exposed to ETS, due to paternal, maternal, and other family member's smoking. Dampness and mold occurred in about a quarter of children's houses in the last 12 months. The vast majority of households $(94.09 \%)$ used non-clean (gas) fuels (versus electricity) and $89.50 \%$ reported home cooking more than 3 days a week. About half of the children had cough with a cold. The prevalence of nightly cough, wheeze, bronchitis and allergic rhinitis were relatively high in the last 12 months, which was $22.48 \%, 24.63 \%, 14.95 \%$ and $15.54 \%$, respectively. The prevalence of ever asthma (2.85\%) and recent asthma (1.07\%) were low. Among all the subjects, 314 (15.29\%) had a higher CRIP score.

Of the 2,306 children, 987 children were measured for their lung function but 73 were excluded due to missing data in analysis of CRIP. We found that 121 (13.24\%) of these children lived in homes with a higher CRIP score. The geometric means of lung function parameters are presented in Table 2. 
Table 2 Characteristics of the study participants and indoor exposure

\begin{tabular}{|c|c|}
\hline Variables & Mean \pm SD $/ \%$ \\
\hline \multicolumn{2}{|l|}{ Questionnaire derived data $(\mathrm{N}=2,306)$} \\
\hline \multicolumn{2}{|l|}{ Subject characteristic } \\
\hline Age, years & $9.83 \pm 0.04$ \\
\hline \multicolumn{2}{|l|}{ Maternal education } \\
\hline Junior high school degree or below & $18.46 \%$ \\
\hline High school & $31.29 \%$ \\
\hline College degree & $28.26 \%$ \\
\hline Bachelor degree & $19.10 \%$ \\
\hline Master degree or above & $2.89 \%$ \\
\hline Maternal asthma & $0.67 \%$ \\
\hline Paternal asthma & $0.90 \%$ \\
\hline \multicolumn{2}{|l|}{ Breastfeeding duration } \\
\hline More than six months & $37.59 \%$ \\
\hline Maternal smoking during pregnancy & $0.45 \%$ \\
\hline \multicolumn{2}{|l|}{ Indoor exposure } \\
\hline ETS & $44.83 \%$ \\
\hline Dampness and molds & $25.69 \%$ \\
\hline Incense burning & $41.66 \%$ \\
\hline Open kitchen & $37.07 \%$ \\
\hline Decoration & $15.70 \%$ \\
\hline High cooking frequency & $89.50 \%$ \\
\hline Pets & $17.08 \%$ \\
\hline Air conditioner use & $89.60 \%$ \\
\hline No kitchen ventilation & $14.56 \%$ \\
\hline Non-clean fuels & $94.09 \%$ \\
\hline Air freshener & $7.14 \%$ \\
\hline Higher CRIP & $15.29 \%$ \\
\hline \multicolumn{2}{|l|}{ Respiratory diseases and symptoms } \\
\hline Cough with a cold & $42.42 \%$ \\
\hline Cough without a cold & $4.92 \%$ \\
\hline Nightly a cough & $22.48 \%$ \\
\hline Phlegm with a cold & $13.83 \%$ \\
\hline Phlegm without a cold & $2.14 \%$ \\
\hline Wheeze last year & $24.63 \%$ \\
\hline
\end{tabular}

Table 2 (continued)
Table 2 (continued)

\begin{tabular}{|c|c|}
\hline Variables & Mean $\pm \mathrm{SD} / \%$ \\
\hline Wheeze with a cold & $6.82 \%$ \\
\hline Wheeze without a cold & $1.43 \%$ \\
\hline Daytime and nightly wheeze & $1.49 \%$ \\
\hline Wheeze while sleeping & $48.18 \%$ \\
\hline Wheeze while speaking & $20.86 \%$ \\
\hline Ever asthma & $2.85 \%$ \\
\hline Recent asthma & $1.07 \%$ \\
\hline Recent bronchitis & $14.95 \%$ \\
\hline Recent pneumonia & $1.07 \%$ \\
\hline Ever allergy & $9.66 \%$ \\
\hline Recent allergy & $4.37 \%$ \\
\hline Recent allergic rhinitis & $15.54 \%$ \\
\hline \multicolumn{2}{|l|}{ Lung function data $(\mathrm{N}=987)$} \\
\hline \multicolumn{2}{|l|}{ Subject characteristic } \\
\hline Age, years & $9.86 \pm 0.05$ \\
\hline Height, cm & $138.53 \pm 0.34$ \\
\hline Weight, kg & $33.24 \pm 0.32$ \\
\hline Sex (girl) & $47.92 \%$ \\
\hline \multicolumn{2}{|l|}{ Lung function } \\
\hline FVC, L & $1.68(1.65,1.72)$ \\
\hline $\mathrm{FEV}_{1}, \mathrm{~L}$ & $1.57(1.55,1.60)$ \\
\hline PEF, L & $2.95(2.90,3.01)$ \\
\hline $\mathrm{FEF}_{25 \%}$, L/S & $2.80(2.74,2.85)$ \\
\hline $\mathrm{FEF}_{25-75 \%}$, L/S & $2.22(2.18,2.26)$ \\
\hline $\mathrm{FEF}_{75 \%}$, L/S & $1.49(1.46,1.52)$ \\
\hline VC, L & $1.91(1.87,1.96)$ \\
\hline MVV, L & $46.88(46.00,47.80)$ \\
\hline Higher CRIP & $13.24 \%$ \\
\hline
\end{tabular}

Spirometric indices, geometric mean $(95 \% \mathrm{Cl})$; maternal asthma or paternal asthma, maternal asthma or paternal report of asthma ever diagnosed by a physician. CRIP, the cumulative risk of indoor pollution. ETS, environmental tobacco smoke; CRIP, cumulative risk of indoor pollution; FVC, forced vital capacity; $\mathrm{FEV}_{1}$, forced expiratory volume in the first second; $\mathrm{FEF}_{25 \%}$, forced expiratory flow at $25 \%$ of expired volume; $\mathrm{FEF}_{25-75 \%}$, forced expiratory flow between $25 \%$ and $75 \%$ of expired volume; $\mathrm{FEF}_{75 \%}$, forced expiratory flow at $75 \%$ of expired volume; VC, vital capacity; MVV, maximum voluntary ventilation. 


\section{Associations between indoor exposure and respiratory bealth outcomes}

Adjusted odds ratios (Table 3) for home dampness and molds in association with cough with or without a cold, phlegm with a cold, wheeze with a cold, wheeze while speaking, recent bronchitis, ever allergy, recent allergy and recent allergic rhinitis were greater than 1 and statistically significant $(\mathrm{P}<0.05)$. Indoor ETS exposure and household decoration in the past year were also associated with a variety of respiratory diseases and symptoms. Children exposed to ETS were 1.37 times more likely to develop phlegm with a cold, 2.94 times more likely for daytime and nightly wheeze, 4.09 times more likely for wheeze during last year, and 3.58 times more likely for wheeze while sleeping. Children who had household decoration in the previous year were more susceptible to cough with a cold, wheeze while sleeping and recent allergy than those without home decoration. The ORs were $>1$ and statistically significant $(\mathrm{P}<0.05)$. The results of unadjusted $\mathrm{ORs}$ are provided in Table S2. The results were similar between unadjusted and adjusted ORs. In the adjusted model, children living in houses with open kitchens were 3.93 times more likely to be at risk for wheeze while sleeping than those living in houses with closed kitchens. It was noted that an open kitchen was a protective factor for ever allergy (OR $=0.62$, 95\% CI: 0.45-0.85), and high cooking frequency was negatively associated with daytime and nightly wheeze and wheeze while sleeping $(\mathrm{P}<0.05)$. To evaluate the combined health effects of kitchen type and cooking frequency to avoid potential confounding, we conducted a sensitivity analysis (Table S3). Children living in residences with an open kitchen and with a high cooking frequency were more likely to develop bronchitis than those living residences with a closed kitchen and a low cooking frequency (OR $=2.51,95 \%$ CI: $1.24-5.09$, Table S4).

\section{Association between indoor exposure and lung function}

The relationships between indoor exposure variables and lung function are shown in Table 4. After adjusting for physiological factors (age, gender, height and weight), home dampness and molds were negatively associated with $\mathrm{FEF}_{25-75 \%}(\mathrm{P}=0.047)$ and $\mathrm{FEF}_{75 \%}(\mathrm{P}=0.037)$. There were significantly negative associations between ETS exposure and VC $(\mathrm{P}=0.022)$, mechanical kitchen ventilation and $\mathrm{PEF}$ $(\mathrm{P}=0.041)$, use of air freshener and $\mathrm{FEF}_{25 \%}(\mathrm{P}=0.032)$. We found statistically significant associations between open kitchens and reductions in $\mathrm{PEF}(\mathrm{P}=0.025), \mathrm{VC}(\mathrm{P}=0.003)$ and $\mathrm{FEF}_{25 \%}(\mathrm{P}=0.044)$, respectively. We also found a statistically significant association between incense burning and reduced $\mathrm{VC}(\mathrm{P}=0.032)$. However, most of the remaining indoor risk factors showed non-significant associations with children's lung function. We also noted kitchen ventilation was significantly and negatively associated with PEF, and theorized that this unexpected association might result from bias due to without considering cooking frequency in the model. A sensitivity analysis was conducted to evaluate the combined effects of kitchen ventilation and cooking frequency to avoid potential confounding (Tables S5,S6). These subgroup models showed that children living in residences without kitchen ventilation, whether with low or high cooking frequency, were more likely to have lower lung function, compared to those living in residences with kitchen ventilation.

After adjusting for age, gender, height, weight, maternal education, breastfeeding duration, and other indoor factors in the model (Table S7), we only found significant associations of open kitchen with reduced $\mathrm{VC}(\mathrm{P}=0.003)$, and the use of air freshener with reduced PEF $(\mathrm{P}=0.038)$, reduced $\mathrm{FEF}_{25-75 \%}(\mathrm{P}=0.044)$ and reduced $\mathrm{FEF}_{25 \%}(\mathrm{P}=0.012)$, respectively. Other indoor risk factors showed negative but nonsignificant associations with the lung function parameters. Findings of the present study provide robust evidence that lung function, as measured by $\mathrm{PEF}, \mathrm{FEF}_{25-75 \%}$ and $\mathrm{FEF}_{25 \%}$, is reduced in children exposed to indoor air freshener. This result is expected because air freshener is an important source of volatile organic compounds (VOCs), most of which have been found to cause adverse respiratory effects (20-22). It was noted, however, that the use frequency and duration of air freshener were not investigated in the current study; thus, the findings should be interpreted with caution.

\section{Association between the CRIP and respiratory diseases and symptoms}

We evaluated the CRIP based on the six risk variables (including dampness and molds, ETS exposure, incense burning, open kitchen, household decoration and cooking frequency). As shown in Table 5, children with a higher CRIP score were more likely to have phlegm without a cold $(\mathrm{OR}=2.06,95 \% \mathrm{CI}: 1.02-4.15)$ than those with a lower CRIP score. As for other respiratory diseases or symptoms, the results indicated that children with a higher CRIP score also had a higher risk. 


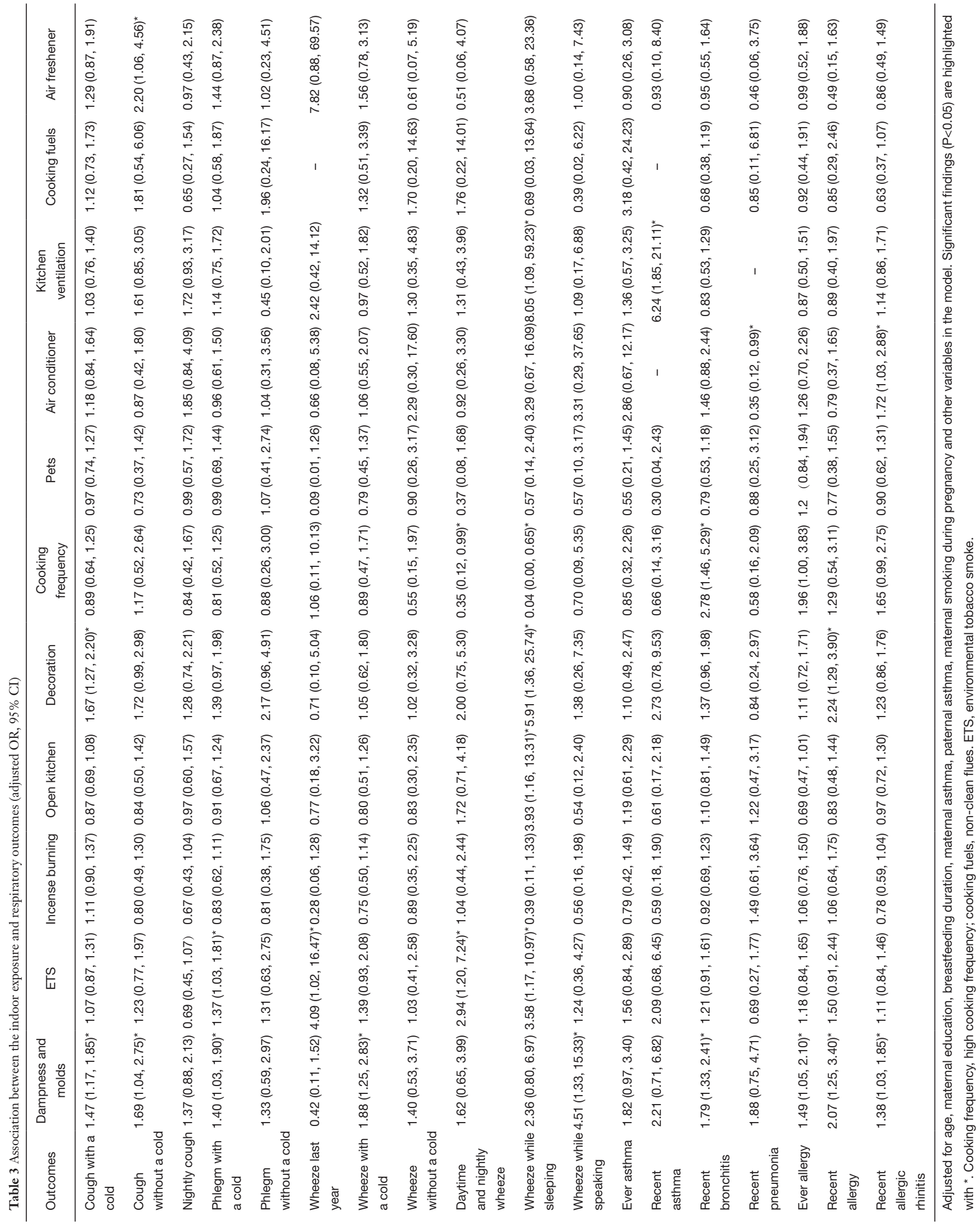




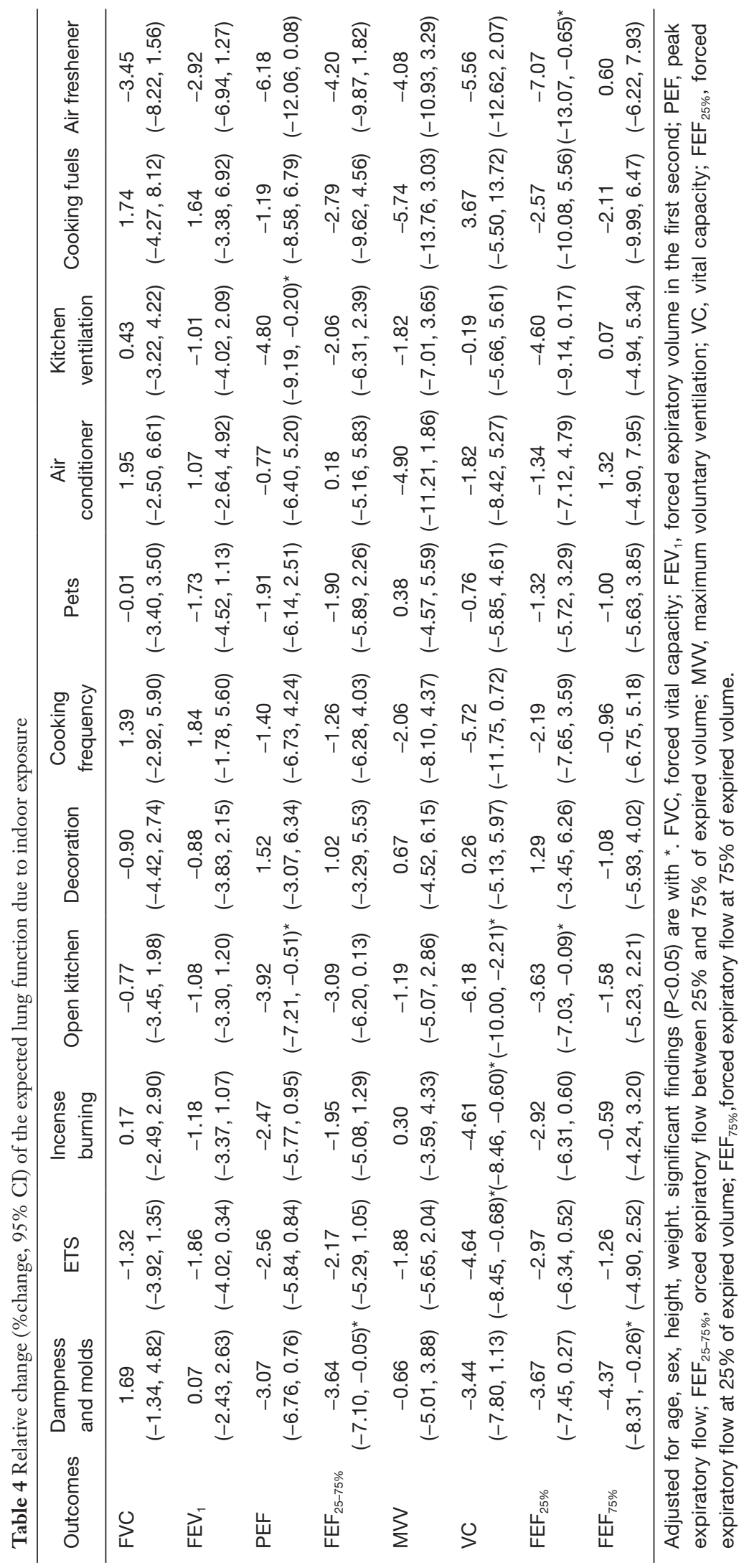


Table 5 Association between the higher CRIP and respiratory outcomes

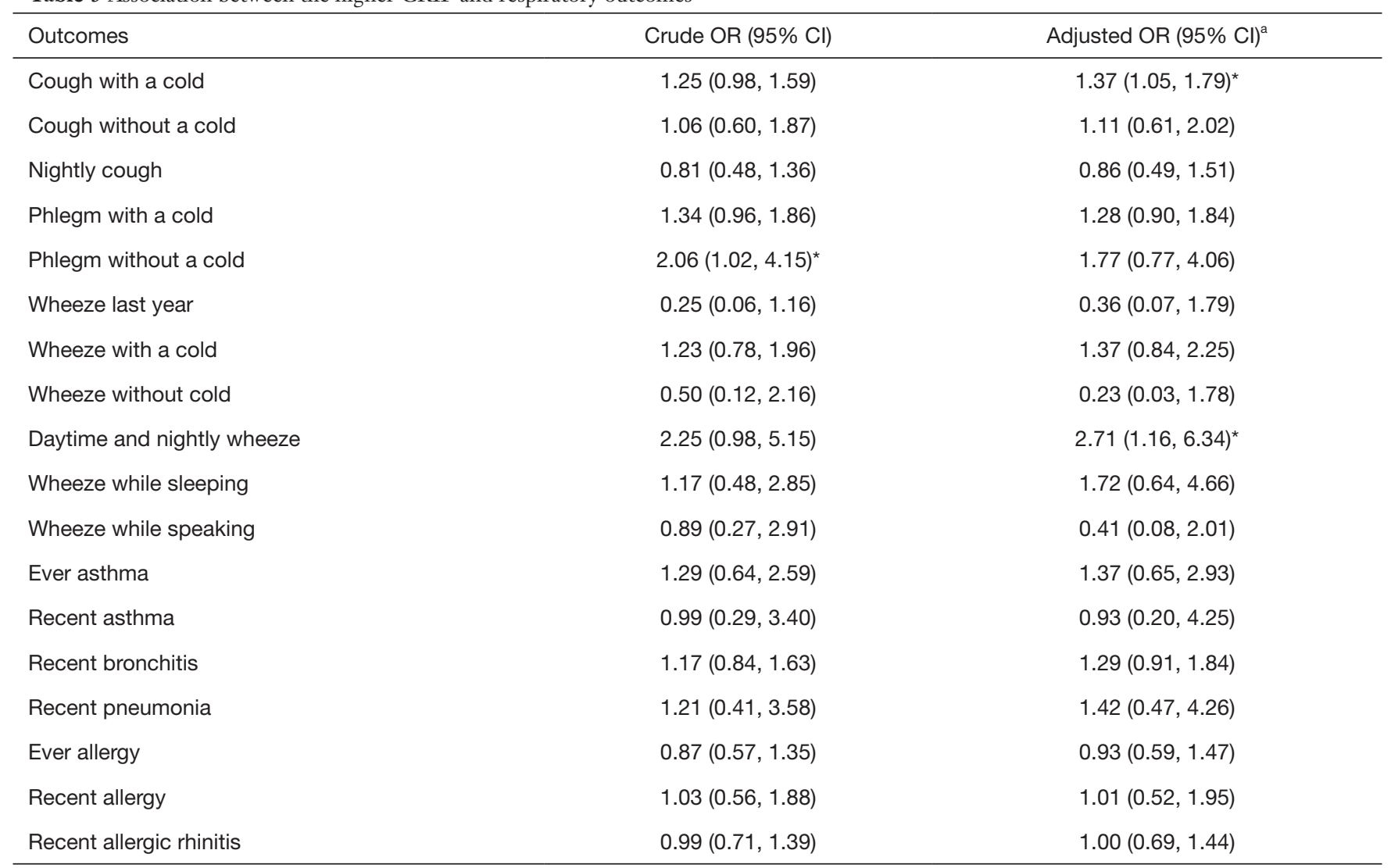

a, adjusted for age, maternal education, breastfeeding duration, maternal asthma, paternal asthma, maternal smoking during pregnancy. All classification variables are binary variables except maternal education. Significant findings $(P<0.05)$ are with * CRIP, cumulative risk of indoor pollution.

After the adjustment for age, maternal education, breastfeeding duration, maternal smoking during pregnancy, maternal asthma and paternal asthma, children with a higher CRIP score were 1.37 times (95\% CI: 1.05-1.79) more likely to have cough with a cold and 2.71 times (95\% CI: 1.16-6.34) more likely to develop daytime and nightly wheeze.

\section{Association between the CRIP and lung function}

As shown in Table 6, after adjusting for age, gender, height and weight in the multivariate linear regression models, we found that higher CRIP scores were significantly associated with lower $\mathrm{VC}$ values $(-6.42 \%, \mathrm{P}=0.034)$. CRIP scores were negatively (without statistical significance) associated with most of the other lung function variables. After further adjusting for maternal education, breastfeeding duration, and maternal smoking during pregnancy, the findings remain unchanged.

\section{Discussion}

Our study presents an approach that can evaluate the CRIP. Home dampness and molds, ETS exposure, incense burning, open kitchen, household decoration and cooking frequency are among the most important predictor variables for children's indoor exposure risks. We found significant effects of home dampness and molds as well as ETS exposure on children's respiratory symptoms and lung function measures. Children living in houses with a higher CRIP score were more likely to report respiratory symptoms and to have reduced lung function.

Previous studies have found associations of home dampness and molds with respiratory diseases and symptoms in children (23-25). Our findings on increased risks of respiratory diseases (i.e., cough with a cold, cough without a cold, wheeze while speaking, recent bronchitis, recent allergy, recent allergic rhinitis) in children living 
Table 6 Relative change (change in\%) of the expected lung function associated with higher CRIP

\begin{tabular}{lcc}
\hline Outcomes & Basic model, \% change $(95 \% \mathrm{Cl})$ & Adjusted model, \% change $(95 \% \mathrm{Cl})$ \\
\hline FVC & $-1.74(-5.62,2.30)$ & $-2.73(-6.90,1.63)$ \\
FEV $_{1}$ & $-1.76(-4.98,1.57)$ & $-2.73(-6.17,0.83)$ \\
PEF & $-2.99(-7.92,2.19)$ & $-3.59(-8.83,1.94)$ \\
FEF $_{25-75 \%}$ & $-1.26(-6.00,3.71)$ & $-2.11(-7.11,3.15)$ \\
MVV & $1.22(-4.68,7.48)$ & $0.16(-6.18,6.93)$ \\
VC & $-6.42(-11.98,-0.52)^{*}$ & $-7.09(-13.02,-0.75)^{*}$ \\
FEF $_{25 \%}$ & $-3.01(-8.08,2.35)$ & $-3.71(-9.08,1.97)$ \\
FEF $_{75 \%}$ & $0.69(-4.86,6.56)$ & $0.04(-5.84,6.28)$ \\
\hline
\end{tabular}

Basic model only adjusted for age, sex, height and weight; adjusted model: adjusted for age, sex, height, weight, maternal education, breastfeeding duration, maternal smoking during pregnancy. Significant findings $(\mathrm{P}<0.05)$ are highlighted with *. FVC, forced vital capacity; $\mathrm{FEV}_{1}$, forced expiratory volume in the first second; PEF, peak expiratory flow; $\mathrm{FEF}_{25-75 \%}$, forced expiratory flow between $25 \%$ and $75 \%$ of expired volume; MVV, maximum voluntary ventilation; $\mathrm{VC}$, vital capacity; $\mathrm{FEF}_{25 \%}$, forced expiratory flow at $25 \%$ of expired volume; $\mathrm{FEF}_{75 \%}$, forced expiratory flow at $75 \%$ of expired volume.

in homes with dampness and molds are consistent with the finding from a birth cohort study of 4,098 children in Sweden. In this 16-year-follow-up study, the presence of home dampness and molds was associated with an increased risk of asthma (OR $=1.31 ; 95 \% \mathrm{CI}: 1.08-1.59)$ and rhinitis $(\mathrm{OR}=1.28$; 95\% CI: $1.04-1.58)$ in children (26). Home dampness exposure in our study was associated with not only increased risk of respiratory symptoms but also reduction in $\mathrm{FEF}_{25-75 \%}$ and $\mathrm{FEF}_{75 \%}$ (Table 4). Most previous studies showed consistent, albeit heterogeneous, negative association of home dampness with acute changes in lung function $(5,27)$. Plausible mechanisms of home dampness and molds adverse effects have been well described $(26,28,29)$. Childhood exposure to dampness and molds may induce respiratory irritation and activate immune system, resulting in chronic respiratory inflammation and other inflammatory diseases such as rhinitis. Bioaerosols (e.g., fungal spore) were also suggested to contribute to the adverse health effects of home dampness as well (30).

A large number of harmful substances in ETS have been confirmed to trigger toxic injury to mucous epithelium and immunocytes, causing long-term inflammation and hyperemia of respiratory airway (31-34), and increasing the ability of cell adherence of microorganism to respiratory epithelial $(35,36)$. These potential pathophysiologic pathways support ETS exposure as a risk factor for respiratory symptoms including bronchitis and wheeze. Our results further demonstrate the harmful effects of ETS exposure on the respiratory health, reflected in increased risks for phlegm with a cold, wheeze last year, daytime and nightly wheeze and wheeze while sleeping. Our finding is consistent with the results of the previous studies (10,23,37-39).

Although the use of household solid fuel has been considered to be the major source of indoor pollution, few of our subjects' households used solid fuels. The majority used gas fuels. We did not find a significant effect of gas fuel use in the present study. A study among 2,289 United Kingdom subjects found that gas cooking (compared to electricity cooking) was significantly associated with increased odds of wheeze in children (OR $=1.47$; 95\% CI: 1.05-1.74) (37). However, a Dutch birth cohort of more than 3,000 children only found a significant association of gas cooking with nasal symptoms, but not with other respiratory diseases or allergic diseases (40). An Australian study including 2,815 participants suggested that gas cooking was slightly associated with lung function reduction in children (41). Considerable inconsistencies among the findings of different studies could be attributable to heterogeneity in the effects of household characteristics and exposure assessment approaches (42).

The random forest model described here is a useful method for variable selection. It allowed for the identification of household risk factors that were associated with children's respiratory diseases or symptoms, and even potential risk factors that were not of concerns in previous studies. It also allowed for estimating variable importance and predicting risk ranking of household environmental risk factors for our study. Based on the random forest 
algorithm, we identified that dampness and molds, ETS exposure, use of mosquito-repellent incense, open kitchen, household decoration and cooking frequency were topranked in terms of variable importance among the indoor environment risk factors. This resulted in the development of the CRIP index. Adjusted for age, maternal education and breastfeeding duration, maternal smoking during pregnancy and other covariates, children with higher CRIP was positively associated with the risks of cough with a cold (OR $=1.37 ; 95 \%$ CI: $1.05-1.79)$ and daytime and nightly wheeze $(\mathrm{OR}=2.71 ; 95 \% \mathrm{CI}$ : 1.16-6.34). And children with a higher CRIP score was negatively associated with FVC, $\mathrm{FEV}_{1}, \mathrm{PEF}, \mathrm{FEF}_{25-75 \%}, \mathrm{VC}$ and $\mathrm{FEF}_{25 \%}$, but statistically significant association was found only for $\mathrm{VC}(\mathrm{P}=0.029)$. Taking combined action of multiple exposure factors into account, our CRIP model provided a comprehensive reflection of the health effects of indoor exposure for children. The CRIP index is straightforward and simple for identifying importance and effects of environmental risk factors. It can be applied to, but not limited to indoor environment, any environmental media to estimate combined effects of multiple risk factors. Our study demonstrates the usefulness of using the random forest data analytic approach in the health risk assessment. Considering the "explosion" in our data collection capacity and the rapid advancement in data science, the application of big data analysis (e.g., machine learning, and deep learning) in environmental health research holds great promise to address multiple risk factors.

There are limitations in our study. The information about indoor exposure for the CRIP index was based on parental-reported questionnaire. The socioeconomic status and outdoor environmental factors of each study subject were not considered or adjusted in the CRIP index due to the lack of data. The cross-sectional study design has its inherent limitations of potential confounding. Finally, data on respiratory symptoms and illnesses were derived from self-reporting via a questionnaire survey, which has potential recall and reporting biases.

\section{Conclusions}

Exposure to home dampness and molds was a risk factor for respiratory health in school children living in Guangzhou and Shenzhen, located in a subtropical region. Given that these southern China coastal cities have many months of high-humidity weather conditions, moisture control is an important preventive measure to reduce children's respiratory symptoms. A Random-Forest based method was useful to generate a CRIP that represents the combined effects of multiple risk factors. Higher CRIP values were associated with increased respiratory symptoms and reduced lung function.

\section{Acknowledgments}

We thank the participants of the two elementary schools in our study for their diligent efforts. We greatly appreciate Dr. Qin Liu (ChongQing Medical University) for her great help in comments and suggestions for the manuscript. We are grateful to Dr. Yajun Chen (Department of Maternal and Child Health, School of Public Health, Sun Yatsen University) and Ms. Lu Deng (Center for Health Promotion for Primary and Secondary Schools, Guangzhou Education Bureau) for the assistance in recruitment by the elementary school in Guangzhou. We thank the volunteers in our group for all the support in the sampling and quality assurance of the study.

Funding: This work was supported by the National Natural Science Foundation of China (grant numbers 41501540 and 91743109) and the Guangdong Province Natural Science Foundation (grant number 2016A030313194).

\section{Footnote}

Provenance and Peer Review: This article was commissioned by the Guest Editor (Junfeng Zhang, Howard Kipen and Haidong Kan) for the focused issue "Children's Respiratory Health and Air Quality" published in Fournal of Thoracic Disease. The article was sent for peer review organized by the Guest Editors and the editorial office.

Conflicts of Interest: All authors have completed the ICMJE uniform disclosure form (available at http:// dx.doi.org/10.21037/jtd.2020.03.92). The issue "Children's Respiratory Health and Air Quality" was commissioned by the editorial office without any funding or sponsorship. JJZ served as the unpaid Guest Editor of the issue. JJZ also serves as an unpaid editorial board member of fournal of Thoracic Disease. The other authors have no other conflicts of interest to declare.

Ethical Statement: The authors are accountable for all aspects of the work in ensuring that questions related to the accuracy or integrity of any part of the work are appropriately investigated and resolved. This study was 
approved by the Duke Kunshan University Institutional Review Board (DKU IRB) (No. FWA00021580), and parents or other guardians of the children signed informed consent.

Open Access Statement: This is an Open Access article distributed in accordance with the Creative Commons Attribution-NonCommercial-NoDerivs 4.0 International License (CC BY-NC-ND 4.0), which permits the noncommercial replication and distribution of the article with the strict proviso that no changes or edits are made and the original work is properly cited (including links to both the formal publication through the relevant DOI and the license). See: https://creativecommons.org/licenses/by-nc-nd/4.0/.

\section{References}

1. Klepeis NE, Nelson WC, Ott WR, et al. The National Human Activity Pattern Survey (NHAPS): a resource for assessing exposure to environmental pollutants. J Expo Anal Environ Epidemiol 2001;11:231-52.

2. Stranger M, Potgieter-Vermaak SS, Van Grieken R. Characterization of indoor air quality in primary schools in Antwerp, Belgium. Indoor Air 2008;18:454-63.

3. Canha N, Freitas MC, Almeida SM, et al. Indoor school environment: easy and low cost to assess inorganic pollutants. J Radioanal Nucl Chem 2010;286:495-500.

4. Lannerö E, Wickman M, van Hage M, et al. Exposure to environmental tobacco smoke and sensitisation in children. Thorax 2008;63:172-6.

5. Holst GJ, Host A, Doekes G, et al. Allergy and respiratory health effects of dampness and dampness-related agents in schools and homes: a cross-sectional study in Danish pupils. Indoor Air 2016;26:880-91.

6. Chao MR, Cooke MS, Kuo CY, et al. Children are particularly vulnerable to environmental tobacco smoke exposure: Evidence from biomarkers of tobaccospecific nitrosamines, and oxidative stress. Environ Int 2018;120:238-45.

7. Dales R, Liu L, Wheeler AJ, et al. Quality of indoor residential air and health. CMAJ 2008;179:147-52.

8. Lin W, Brunekreef B, Gehring U. Meta-analysis of the effects of indoor nitrogen dioxide and gas cooking on asthma and wheeze in children. Int J Epidemiol 2013;42:1724-37.

9. Vesper $\mathrm{S}$, Wymer L. The relationship between environmental relative moldiness index values and asthma. Int J Hyg Environ Health 2016;219:233-8.
10. Olaniyan T, Dalvie MA, Roosli M, et al. Asthma-related outcomes associated with indoor air pollutants among schoolchildren from four informal settlements in two municipalities in the Western Cape Province of South Africa. Indoor Air 2019;29:89-100.

11. Breiman L. Random forests. Mach Learn 2001;45:5-32.

12. Lunetta KL, Hayward LB, Segal J, et al. Screening largescale association study data: exploiting interactions using random forests. BMC Genet 2004;5:32.

13. Hoffmann K, Firth MJ, Beesley AH, et al. Translating microarray data for diagnostic testing in childhood leukaemia. BMC Cancer 2006;6:229.

14. Chen X, Liu CT, Zhang M, et al. A forest-based approach to identifying gene and gene gene interactions. Proc Natl Acad Sci U S A 2007;104:19199-203.

15. Chen $X$, Ishwaran $H$. Random forests for genomic data analysis. Genomics 2012;99:323-9.

16. Zhang JJ, Hu W, Wei F, et al. Children's Respiratory Morbidity Prevalence in Relation to Air Pollution in Four Chinese Cities. Environ Health Perspect 2002;110:961-7.

17. Yin Z, Huang $X, H e$ L, et al. Trends in ambient air pollution levels and PM2.5 chemical compositions in four Chinese cities from 1995 to 2017. J Thorac Dis 2020:12:6396-410.

18. Zhang Q, Xiao MZ, Singh VP, et al. Regionalization and spatial changing properties of droughts across the Pearl River basin, China. Journal of Hydrology 2012;472473:355-66.

19. Ferris BG. Epidemiology Standardization Project (American Thoracic Society). Am Rev Respir Dis 1978;118:1-120.

20. Kim S, Hong SH, Bong CK, et al. Characterization of air freshener emission: the potential health effects. J Toxicol Sci 2015;40:535-50.

21. Elliott L, Longnecker MP, Kissling GE, et al. Volatile organic compounds and pulmonary function in the Third National Health and Nutrition Examination Survey, 19881994. Environ Health Perspect 2006;114:1210-4.

22. Anderson RC, Anderson JH. Toxic effects of air freshener emissions. Arch Environ Health 1997;52:433-41.

23. Mommers M, Jongmans-Liedekerken AW, Derkx R, et al. Indoor environment and respiratory symptoms in children living in the Dutch-German borderland. Int J Hyg Environ Health 2005;208:373-81.

24. Mendell MJ, Mirer AG, Cheung K, et al. Respiratory and allergic health effects of dampness, mold, and dampnessrelated agents: a review of the epidemiologic evidence. Environ Health Perspect 2011;119:748-56. 
25. Zacharasiewicz A, Zidek T, Haidinger G, et al. Symptoms suggestive of atopic rhinitis in children aged 6-9 years and the indoor environment. Allergy 2000;5 5:945-50.

26. Thacher JD, Gruzieva O, Pershagen G, et al. Mold and dampness exposure and allergic outcomes from birth to adolescence: data from the BAMSE cohort. Allergy 2017;72:967-74.

27. Simoni M, Cai GH, Norback D, et al. Total viable molds and fungal DNA in classrooms and association with respiratory health and pulmonary function of European schoolchildren. Pediatr Allergy Immunol 2011;22:843-52.

28. Fisk WJ, Lei-Gomez Q, Mendell MJ. Meta-analyses of the associations of respiratory health effects with dampness and mold in homes. Indoor Air 2007;17:284-96.

29. Karvonen AM, Hyvarinen A, Korppi M, et al. Moisture damage and asthma: a birth cohort study. Pediatrics 2015;135:e598-606.

30. Tischer CG, Heinrich J. Exposure assessment of residential mould, fungi and microbial components in relation to children's health: achievements and challenges. Int J Hyg Environ Health 2013;216:109-14.

31. Matulionis DH. Effects of cigarette smoke generated by different smoking machines on pulmonary macrophages of mice and rats. J Anal Toxicol 1984;8:187-91.

32. Fukuma M, Seto Y, Fukushima K, et al. The effect of food dye and other environmental substances on the host defense reaction in mice in relation to virus infection. J Toxicol Sci 1986;11:169-77.

33. Nair MP, Kronfol ZA, Schwartz SA. Effects of alcohol and nicotine on cytotoxic functions of human lymphocytes. Clin Immunol Immunopathol 1990;54:395-409.

34. Hasséus B, Wallstrom M, Osterdahl BG, et al.

Cite this article as: Lin J, Lin W, Yin Z, Fu X, Mai D, Fu S, Zhang JJ, Gong J, Feng N, He L. Respiratory health effects of residential individual and cumulative risk factors in children living in two cities of the Pearl River Delta Region, China. J Thorac Dis 2020;12(10):6342-6355. doi: 10.21037/jtd.2020.03.92
Immunotoxic effects of smokeless tobacco on the accessory cell function of rat oral epithelium. Eur J Oral Sci 1997;105:45-51.

35. Fainstein V, M.Musher D. Bacterial Adherence to Pharyngeal Cells in Smokers, Nonsmokers, and Chronic Bronchitics. Infect Immun 1979;26:178-82.

36. Raman AS, Swinburne AJ, Fedullo AJ. Pneumococcal adherence to the buccal epithelial cells of cigarette smokers. Chest 1983;83:23-7.

37. de Bilderling G, Chauhan AJ, Jeffs JA, et al. Gas cooking and smoking habits and the risk of childhood and adolescent wheeze. Am J Epidemiol 2005;162:513-22.

38. He QQ, Wong TW, Du L, et al. Environmental tobacco smoke exposure and Chinese schoolchildren's respiratory health: a prospective cohort study. Am J Prev Med 2011;41:487-93.

39. Liu MM, Wang D, Zhao Y, et al. Effects of outdoor and indoor air pollution on respiratory health of Chinese children from 50 kindergartens. J Epidemiol 2013;23:280-7.

40. Willers SM, Brunekreef B, Oldenwening M, et al. Gas cooking, kitchen ventilation, and asthma, allergic symptoms and sensitization in young children--the PIAMA study. Allergy 2006;61:563-8.

41. Moshammer H, Fletcher T, Heinrich J, et al. Gas cooking is associated with small reductions in lung function in children. Eur Respir J 2010;36:249-54.

42. Dong GH, Qian Z, Fu Q, et al. A Multiple Indicators Multiple Cause (MIMIC) model of respiratory health and household factors in Chinese children: the seven Northeastern cities (SNEC) study. Matern Child Health J 2014;18:129-37. 


\section{Statistical analysis: variable important measures by random forest}

The random forest algorithm is a powerful classification and regression approach capable of measuring variable importance and identifying the interaction of variables to enhance the predictive accuracy. The algorithm operates by extracting several subsamples, forming bootstrap training sets, generating a large number of decision trees, and letting these classifiers "vote" to form the final predictor (11).

Our study included 11 indoor environmental risk factors (i.e., home dampness and molds, ETS exposure, incense burning, open kitchen, household decoration, cooking frequency, pets, use of air conditioner, kitchen ventilation, cooking fuels, and use of air freshener) and 18 health outcomes (cough with a cold, cough without a cold, nightly cough, phlegm with a cold, phlegm without a cold, wheeze last year, wheeze with a cold, wheeze without a cold, daytime and nightly wheeze, wheeze while sleeping, wheeze while speaking, ever asthma, recent asthma, Recent bronchitis, recent pneumonia, ever allergy, recent allergy, recent allergic rhinitis). To perform the random forest analyses, first, several $(\mathrm{N}=500)$ bootstrap samples were randomly drawn from the original data as the training set data. The training sets were used to establish unpruned classification trees with square root of $M(M=11$, representing 11 indoor environmental risk factors) predictors randomly sampled. The remaining 1/3 out-of-bag (OOB) samples, which were not included in the bootstrap samples, were used for crossvalidation. Finally, based on the Gini Index, we evaluated the importance of predictors and ranked the risk of 11 indoor environmental risk factors.

The 11 indoor variables were ranked in the order of smallest to largest in variable importance measures from each forest $(\mathrm{N}=18)$. We then assigned a weight to each indoor variable corresponding to the ranks where a variable appeared. Finally, the total score of variable importance measures for each variable was obtained by summing up its weight within each ranked list (Table S1).

Five random forest models where the OOB error were more than $20 \%$ were excluded, including the forest with the dependent variables of cough with a cold, night cough, wheeze, wheeze while sleeping and wheeze while speaking. The total scores of variable importance measures for each variable of the rest 13 models was also provided in the Table S1. The orders of variable importance were similar whether the 5 forests were excluded or not. 
Table S1 The total important scores of the indoor exposure factors

\begin{tabular}{|c|c|c|c|c|}
\hline \multirow{2}{*}{ Factors } & \multicolumn{2}{|c|}{18 forests } & \multicolumn{2}{|c|}{13 forests } \\
\hline & Total important Scores & The important sequence & Total important Scores & The important sequence \\
\hline Dampness and molds & 172 & 1 & 124 & 1 \\
\hline ETS & 158 & 2 & 118 & 2 \\
\hline Incense burning & 158 & 3 & 114 & 3 \\
\hline Open kitchen & 138 & 4 & 98 & 4 \\
\hline Decoration & 114 & 5 & 92 & 5 \\
\hline Cooking frequency & 105 & 6 & 72 & 6 \\
\hline Pets & 101 & 7 & 66 & 7 \\
\hline Air conditioner & 79 & 8 & 50 & 9 \\
\hline Kitchen ventilation & 78 & 9 & 60 & 8 \\
\hline Cooking fuels & 44 & 10 & 33 & 10 \\
\hline Air freshener & 41 & 11 & 31 & 11 \\
\hline
\end{tabular}

Table S2 Association between the indoor exposure and respiratory outcomes (crude OR and 95\% CI)

\begin{tabular}{|c|c|c|c|c|c|c|c|c|c|c|}
\hline Outcomes & $\begin{array}{l}\text { Dampness and } \\
\text { molds }\end{array}$ & ETS & Incense burning & Open kitchen & Decoration & $\begin{array}{l}\text { Cooking } \\
\text { frequency }\end{array}$ & Pets & Air conditioner & $\begin{array}{c}\text { Kitchen } \\
\text { ventilation }\end{array}$ & Cooking fuels \\
\hline
\end{tabular}

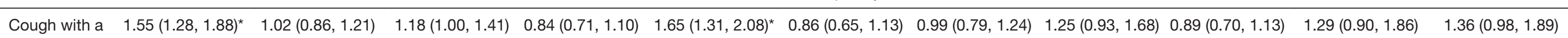
cold

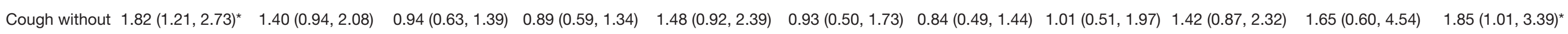
a cold

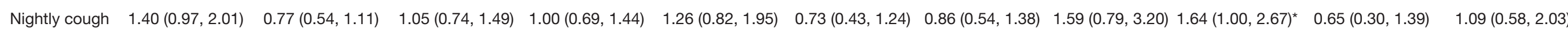

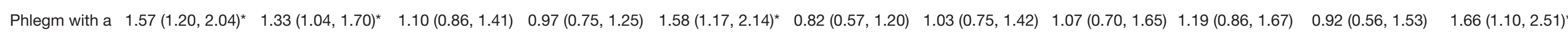
cold

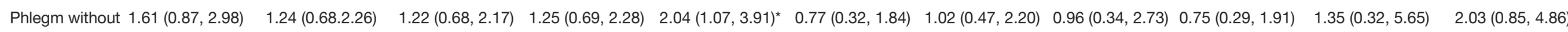
a cold

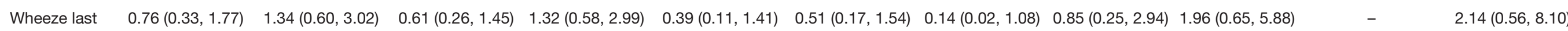
year

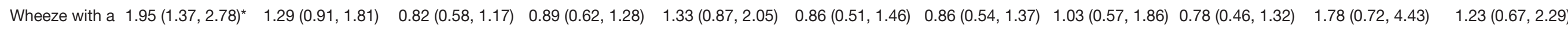
cold

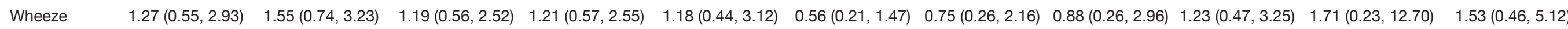
without a cold

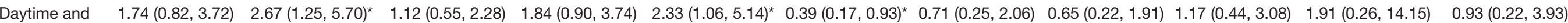
nightly wheeze

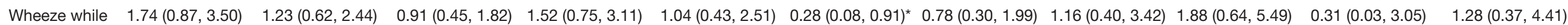
sleeping

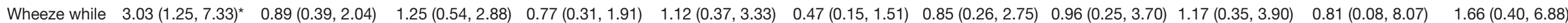
speaking

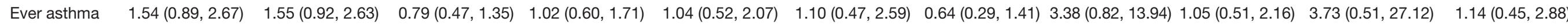

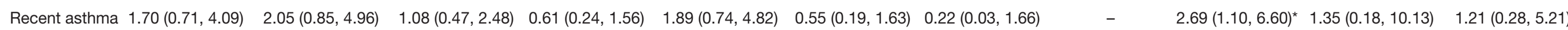

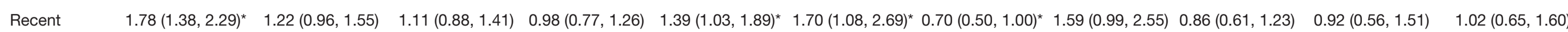
bronchitis

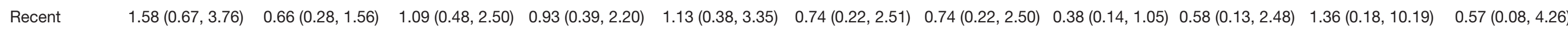
pneumonia

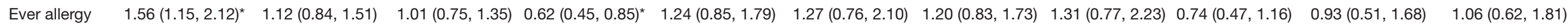

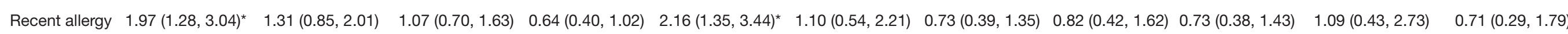

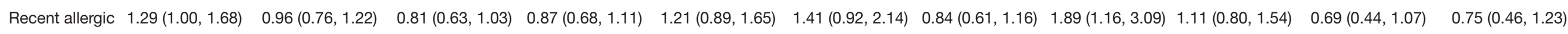
rhinitis

Cooking frequency: high cooking frequency. Cooking fuels: no-clean flues. Significant findings $(P<0.05)$ are with * 

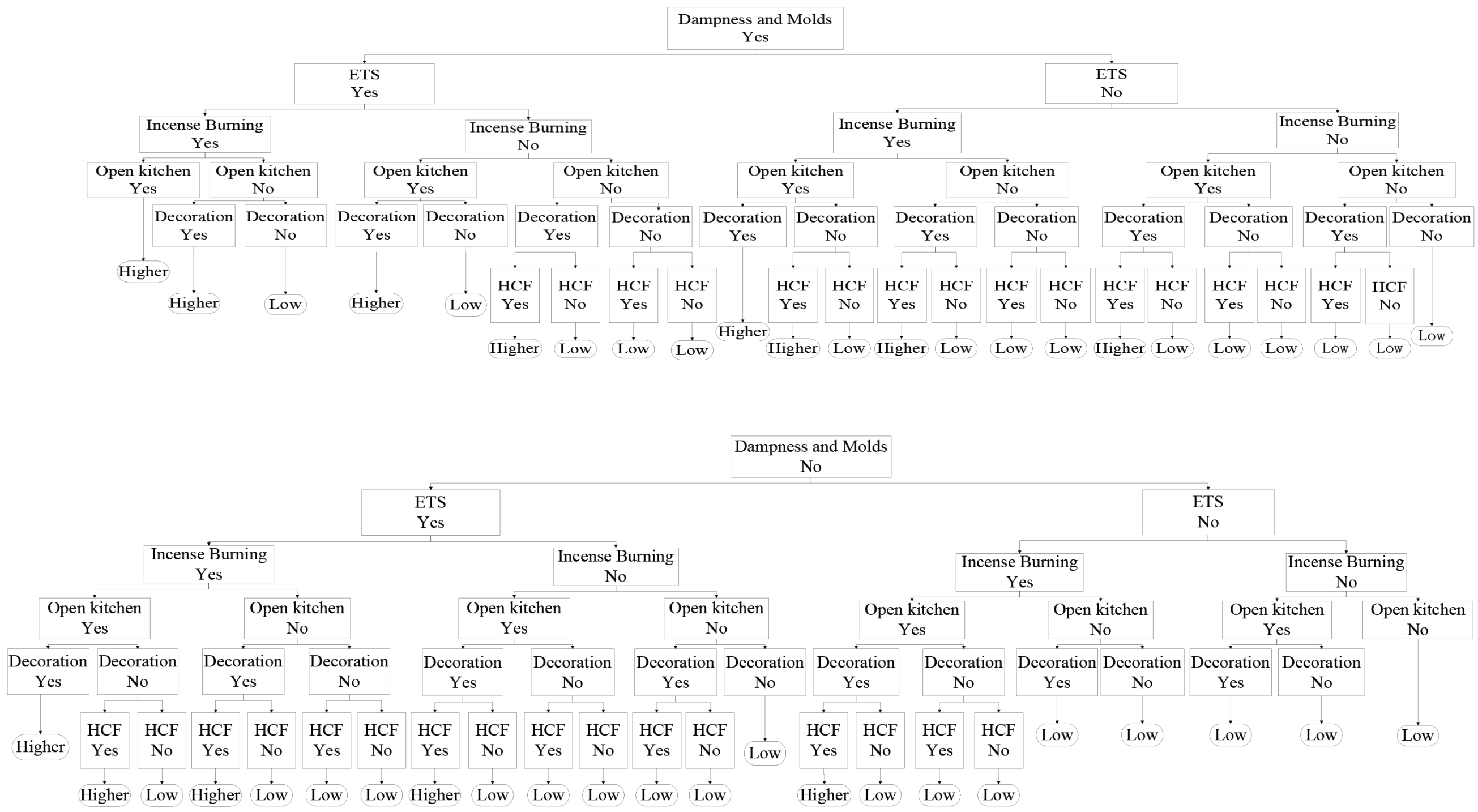

Figure S1 Stratification schemes according to the CRIP model (HCF). CRIP, the cumulative risk of indoor pollution; HCF, high cooking frequency. 
Table S3 Description of the open kitchen and high cooking frequency $(\mathrm{N}=2,253)$

\begin{tabular}{lcc}
\hline Factors & $\mathrm{N}=2,306$ & Frequency \\
\hline Closed kitchen and low cooking frequency & 145 & $6.44 \%$ \\
Closed kitchen and high cooking frequency & 1,273 & $56.50 \%$ \\
Open kitchen and low cooking frequency & 91 & $4.04 \%$ \\
Open kitchen and high cooking frequency & 744 & $33.02 \%$ \\
\hline
\end{tabular}

Table S4 Association between the open kitchen and high cooking frequency and respiratory outcomes (crude OR and 95\% CI)*

\begin{tabular}{|c|c|c|c|}
\hline Outcomes & $\begin{array}{l}\text { Closed kitchen and high cooking } \\
\text { frequency }\end{array}$ & $\begin{array}{l}\text { Open kitchen and low cooking } \\
\text { frequency }\end{array}$ & $\begin{array}{l}\text { Open kitchen and high cooking } \\
\text { frequency }\end{array}$ \\
\hline Cough with a cold & $0.97(0.68,1.37)$ & $1.12(0.66,1.92)$ & $0.79(0.55,1.14)$ \\
\hline Nightly cough & $0.74(0.37,1.45)$ & $1.05(0.39,2.86)$ & $0.72(0.35,1.47)$ \\
\hline Phlegm with a cold & $0.92(0.56,1.50)$ & $1.26(0.62,2.57)$ & $0.85(0.51,1.42)$ \\
\hline Wheeze last year & $0.59(0.10,3.49)$ & $1.33(0.16,11.07)$ & $0.69(0.11,4.44)$ \\
\hline Wheeze with a cold & $1.42(0.64,3.14)$ & $2.42(0.88,6.62)$ & $1.09(0.48,2.50)$ \\
\hline Wheeze without a cold & $0.53(0.15,1.87)$ & $1.11(0.18,6.76)$ & $0.65(0.18,2.40)$ \\
\hline Wheeze while speaking & $0.54(0.09,3.17)$ & $1.00(0.11,8.85)$ & $0.32(0.05,2.25)$ \\
\hline Ever asthma & $2.14(0.51,8.99)$ & $3.32(0.59,18.51)$ & $1.90(0.44,8.26)$ \\
\hline Recent asthma & $0.84(0.19,3.73)$ & $1.63(0.23,11.83)$ & $0.39(0.07,2.16)$ \\
\hline Recent bronchitis & $2.71(1.36,5.43)^{\star}$ & $2.34(0.94,5.81)$ & $2.51(1.24,5.09)^{*}$ \\
\hline Recent pneumonia & $0.73(0.16,3.29)$ & $0.82(0.07,9.15)$ & $0.59(0.12,2.97)$ \\
\hline Ever allergy & $1.50(0.79,2.84)$ & $0.88(0.31,2.47)$ & $0.90(0.45,1.77)$ \\
\hline Recent allergy & $1.42(0.56,3.61)$ & $0.97(0.23,4.17)$ & $0.87(0.32,2.34)$ \\
\hline
\end{tabular}

${ }^{*}$, referring to closed kitchen and low cooking frequency. Significant findings $(P<0.05)$ are with *. 
Table S5 Description of the kitchen ventilation and cooking frequency $(\mathrm{N}=968)$

\begin{tabular}{lcc}
\hline Factors & N=968 & Frequency \\
\hline Kitchen ventilation and low cooking frequency & 76 & $7.85 \%$ \\
Kitchen ventilation and high cooking frequency & 750 & $77.48 \%$ \\
No kitchen ventilation and low cooking frequency & 20 & $2.07 \%$ \\
No kitchen ventilation and high cooking frequency & 122 \\
\hline
\end{tabular}

Table S6 Relative change* (\% change, 95\% CI) of the expected lung function due to kitchen ventilation and cooking frequency

\begin{tabular}{lccc}
\hline Outcomes & $\begin{array}{c}\text { Kitchen ventilation and high cooking } \\
\text { frequency }\end{array}$ & $\begin{array}{c}\text { No kitchen ventilation and low cooking } \\
\text { frequency }\end{array}$ & $\begin{array}{c}\text { No kitchen ventilation and high cooking } \\
\text { frequency }\end{array}$ \\
\hline FVC & $-0.79(-5.52,4.17)$ & $-8.55(-17.4,1.25)$ & $0.93(-4.87,7.08)$ \\
FEV & $-0.39(-4.33,3.71)$ & $-9.85(-17.13,-1.93)^{\#}$ & $-0.08(-4.85,4.93)$ \\
PEF & $-3.29(-9.15,2.95)$ & $-11.08(-21.96,1.31)$ & $-7.09(-13.88,0.23)$ \\
FEF $_{25-75 \%}$ & $-1.26(-6.92,4.74)$ & $-2.05(-13.40,10.78)$ & $-3.53(-10.19,3.63)$ \\
MVV & $-4.02(-10.64,3.10)$ & $-10.18(-22.64,4.27)$ & $-4.64(-12.56,4.00)$ \\
VC & $-7.03(-13.71,0.16)$ & $-6.48(-19.94,9.25)$ & $-6.6(-14.66,2.23)$ \\
FEF $_{25 \%}$ & $-3.87(-9.88,2.54)$ & $-10.16(-21.48,2.80)$ & $-7.55(-14.51,-0.02)^{\#}$ \\
FEF $_{75 \%}$ & $-0.30(-6.89,6.75)$ & $1.85(-11.69,17.46)$ & $-0.94(-8.82,7.61)$ \\
\hline
\end{tabular}

*, referring to kitchen ventilation and low cooking frequency. Adjusted for age, sex, height, weight. Significant findings $(\mathrm{P}<0.05)$ are with ${ }^{\#}$. 
Table S7 Relative change (\%change, 95\% CI) of the expected lung function due to indoor exposure

\begin{tabular}{|c|c|c|c|c|c|c|c|c|c|c|c|}
\hline Outcomes & Dampness and molds & ETS & Incense burning & Open kitchen & Decoration & Cooking frequency & Pets & Air conditioner & Kitchen ventilation & Cooking fuels & Air freshener \\
\hline FVC & $1.13(-2.26,4.64)$ & $-1.65(-4.69,1.49)$ & $0.10(-2.98,3.28)$ & $-2.07(-5.28,1.25)$ & $-0.48(-4.58,3.79)$ & $0.79(-4.12,5.94)$ & $3.22(-0.78,7.38)$ & $-0.19(-5.15,5.02)$ & $-1.09(-5.52,3.54)$ & $0.35(-6.42,7.61)$ & $-1.43(-7.30,4.81)$ \\
\hline $\mathrm{FEV}_{1}$ & $-0.03(-2.83,2.84)$ & $-1.90(-4.43,0.70)$ & $-0.89(-3.44,1.72)$ & $-1.55(-4.24,1.22)$ & $-0.38(-3.81,3.16)$ & $1.83(-2.31,6.14)$ & $1.55(-1.73,4.95)$ & $-0.56(-4.68,3.75)$ & $-1.50(-5.18,2.32)$ & $0.13(-5.52,6.13)$ & $-1.82(-6.71,3.32)$ \\
\hline PEF & $-3.74(-7.86,0.58)$ & $-2.36(-6.23,1.66)$ & $-3.01(-6.82,0.96)$ & $-2.57(-6.65,1.69)$ & $4.65(-0.85,10.45)$ & $-0.13(-6.33,6.48)$ & $2.50(-2.57,7.84)$ & $-1.72(-7.94,4.92)$ & $-2.61(-8.17,3.28)$ & $-4.58(-12.77,4.37)$ & $-8.00(-14.97,-0.46)^{*}$ \\
\hline $\mathrm{FEF}_{25}-75 \%$ & $-3.46(-7.36,0.60)$ & $-1.83(-5.49,1.97)$ & $-2.66(-6.27,1.08)$ & $-2.85(-6.68,1.14)$ & $1.92(-3.13,7.23)$ & $0.66(-5.22,6.91)$ & $1.87(-2.88,6.85)$ & $1.09(-4.93,7.50)$ & $0.12(-5.26,5.81)$ & $-4.01(-11.78,4.44)$ & $-7.32(-13.94,-0.19)^{\star}$ \\
\hline MVV & $-0.70(-5.86,4.75)$ & $-1.77(-6.48,3.18)$ & $0.23(-4.55,5.25)$ & $-3.13(-8.05,2.05)$ & $2.28(-4.23,9.24)$ & $-0.79(-8.24,7.27)$ & $2.87(-3.30,9.44)$ & $-6.33(-13.50,1.45)$ & $0.30(-6.63,7.75)$ & $-7.15(-16.77,3.59)$ & $-5.74(-14.37,3.77)$ \\
\hline vc & $-3.35(-8.22,1.77)$ & $-3.72(-8.19,0.98)$ & $-3.42(-7.89,1.25)$ & $-7.37(-11.93,-2.57)^{\star}$ & $0.64(-5.56,7.26)$ & $-6.48(-13.29,0.85)$ & $1.42(-4.47,7.68)$ & $-4.11(-11.22,3.57)$ & $0.42(-6.30,7.62)$ & $4.13(-6.32,15.75)$ & $-4.31(-12.80,5.01)$ \\
\hline $\mathrm{FEF}_{25 \%}$ & $-3.93(-8.15,0.48)$ & $-2.84(-6.78,1.26)$ & $-3.39(-7.29,0.66)$ & $-2.17(-6.37,2.21)$ & $4.36(-1.26,10.31)$ & $-1.08(-7.37,5.64)$ & $3.53(-1.73,9.06)$ & $-2.23(-8.57,4.56)$ & $-2.38(-8.09,3.69)$ & $-5.95(-14.21,3.12)$ & $-9.83(-16.83,-2.23)^{*}$ \\
\hline
\end{tabular}

Adjusted for age, sex, height, weight, maternal education, breastfeeding duration, and other variables in model. Significant findings $(\mathrm{P}<0.05)$ are with *. 